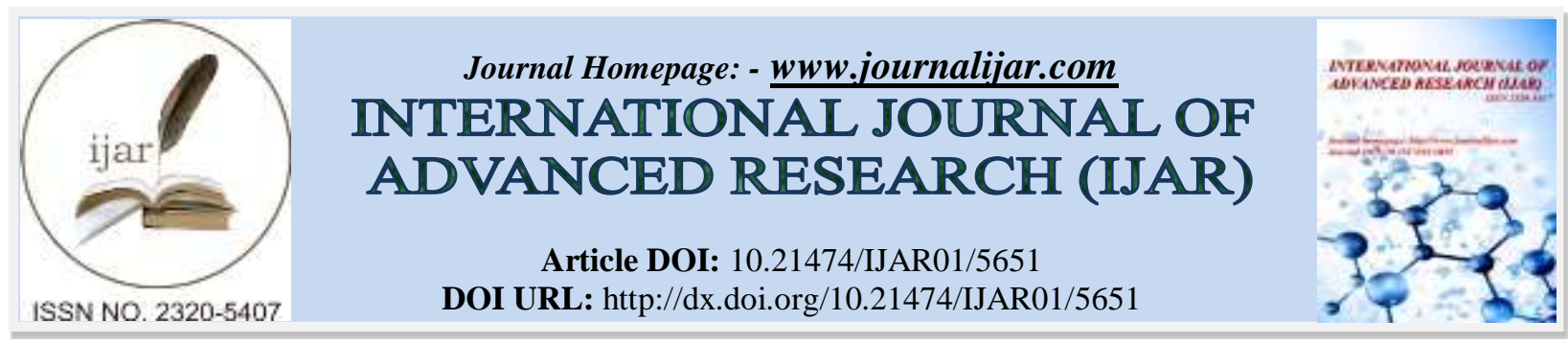

RESEARCH ARTICLE

\title{
DERMATOGLYPHICS AND PERIODONTAL DISEASES-A POSSIBLE RELATION FOR EARLY PREDICTION?
}

\section{Dr. Harikrishna Reddy, Dr. Praveen Kumar and Dr. Atif Abdul Bari.}

\section{Manuscript Info}

[.........................

Manuscript History

Received: 18 August 2017

Final Accepted: 20 September 2017

Published: October 2017

Key words:-

Dermatoglyphics, Diagnosis,

Periodontitis, Prediction, Susceptibility.

\section{Abstract}

Periodontitis is a disease affecting the oral cavity resulting in loss of teeth and it is the second major cause after dental caries resulting in edentulism, the diagnosis of this disease at the earliest possible stage is key for its successful treatment. The diagnostic aids currently available are depending on evaluation of clinical signs and symptoms and the advanced diagnostics aid aim at evaluating microbial profile of the affected sites which are very expensive and cannot be used as a chair side aid. The prediction of a disease by any means may be really an indispensible tool when it comes to minimizing the morbidity of this disease, recent trails which were carried out to evaluate any possible link with the dermatoglyphics (finger print pattern) and susceptibility of an individual to a particular disease has yielded some valuable information in case of some medical conditions. This study deals with the search of any possible link between dermatoglyphics and periodontitis and evaluation of the applicability of previous study results in the participants of this study.

Copy Right, IJAR, 2017,. All rights reserved.

\section{Introduction:-}

Dermatoglyphics,according to Harold Cummins and Midlo in 1926 refers to the branch of science which studies the patterns of skins (dermal) ridges present on the fingers, toes and the soles of human ${ }^{1}$. Dermatoglyphics is derived from the greek words "Derma" and "Glyphe" which mean skin and carving or pattern,these unusual patterns may indicate abnormalities of both gene and chromosomes consistent with diseases.

Finger print is an individual characteristic.The prints are found on Palm and soles of feet, scientifically, no two people can have the same fingerprints. Once a child is born his fingerprints are completely developed and they remain unchanged during an individual's lifetime. Fingerprints are formed between 13th to 19th weeks in the womb when the fetus is developing. These are developed in tandem with brain cells development.

There have been many efforts worldwide in the past and at present in the field of science and health to investigate this unique identification characteristic of an individual to assess his susceptibility/probability to identify and detect its value in diagnosis of various developmental and/or acquired disease at present or in due course of his life.

\section{History of dermatoglyphics:-}

Archaeologists have discovered fingerprints pressed into clay tablet as contract agreement records dating back to 1792-1750 B.C. in Babylon. In ancient China, it was a common practice to use inked fingerprints on all official documents such as contracts and/or, loans. The oldest known document showing fingerprints dates from the third 
century B.C. Chinese historians have found finger and palmar prints pressed into clay and wood writing surfaces and have summarized that they were used for official seals and legal documentations. ${ }^{2}$ Johann Christoph Andreas Mayer followed this work in 1788 by describing that 'the arrangement of skin ridges is never duplicated in two persons'. He was probably the first to recognize this fact. Dermatoglyphics is the scientific study of papillary ridges in the palm of the hands and soles of the feet (Purkinje 1823). ${ }^{3}$ For nearly a century and a half, there were no notable advances although in 1823, Jan Evangelist Purkyn described nine distinct fingerprint patterns including loops, spirals, circles and double whorls. ${ }^{4}$ The importance of dermatoglyphics for practical purposes dates back to ancient China (1839) where it was used in the sale of the land. The deal of the land carried the impression of the finger prints as an acknowledgement of the deal. ${ }^{5}$ Sir William Herschel began the collection of fingerprints in 1856 . He noted the patterns to be unique to each person and not altered by age. ${ }^{2}$ The first systematic study of the whole subject, however, was carried-out by Francis Galton around the year 1892. He divided the ridge patterns on the distal phalanges of the fingertips into three groups namely, arches, loops and whorls. ${ }^{6,7}$ Lauter (1912) provided the history of the fingerprint system. Hersched (1916) traced the origin of the fingerprints. Cummins (1927) found the impression of a thumb print on clay. Heindl (1929) reported the first fingerprint for identification purposes in Germany. ${ }^{5}$ Cummins (1930) exhibited the first fingerprint carving of the stone age. De Forest (1930) traced dactyloscopy in the United States of America. Wilton (1938) published a book, Finger Prints History, Law and Romance. Myers (1939) provided the history of identification of fingerprints. Penrose (1968) finally drafted the memorandum on dermatoglyphics nomenclature. ${ }^{5}$

\subsection{Developmental process of dermatoglyphics}

Dermal ridge differentiation takes place early in fetal development. Ridges develop in relation to the volar pads. The resulting ridge configurations are genetically determined and influenced only by genetic and environmental factors during their developmental stages. Fetal volar pads are mound-shaped elevations of the mesenchymal tissues situated above the proximal ends of the most distal metacarpal bones on each finger, in each interdigital area, in the Thenar and hypothenar (HY) areas of the palms and soles, and in the calcar area of the soles. The formation of these pads is first visible on the fingertips during $6^{\text {th }}-7^{\text {th }}$ week of embryonic development. The pads become very prominent during the subsequent weeks, diminish in the $5^{\text {th }}$ month while disappearing completely in the $6^{\text {th }}$ month. Within this period, the dermal ridges coalesce into specific patterns, replacing the volar pads. The presence of the volar pads as well as their size and position are to a large extent responsible for the configuration of papillary ridge patterns. For example, small pads would result in a simple pattern (arch) whereas more prominent pads would tend to lead to the development of larger and more complex systems of ridge configurations including loops and whorls. ${ }^{8,9}$ The epidermal ridge patterns are completed only after the sixth pre-natal month when the glandular folds are fully formed and after the sweat gland secretion and keratinization starts. At around this time, the configurations on the skin surface begin to reflect the underlying patterns. The surface epidermal furrows correspond to the furrow folds of the stratum germinativum and each epidermal ridge is formed above a glandular fold. ${ }^{9}$ Several hypotheses have been formulated concerning the forces that are responsible for the development of these specific ridge patterns. Few have speculated that the dermal ridge configurations are the result of physical and topographic growth forces. It is believed that the tensions and pressures in the skin during early embryogenesis determine the directions of the epidermal ridges. ${ }^{9}$ Some studies have also described that the arrangement of blood vessels and nerve pairs under the smooth epidermis exists shortly before glandular folds and have speculated that the folds are induced by the blood vessel-nerve pairs. ${ }^{8}$ Cummins (1935) observed the ridge configurations of congenitally malformed hands and proposed that the direction of epidermal ridges is determined by growth forces and the contour of volar skin at the time of ridgeformation. ${ }^{8,9}$

\subsection{Dermatoglyphic pattern configurations in fingers}

The ridge patterns on the distal phalanges of the fingertips are divided into three groups: Arches, loops and whorls [Figure 1]. ${ }^{6,8}$ Arches are formed by a succession of more or, less parallel ridges which traverse the pattern area and form a curve that is concave proximally [Fig 1]a. The arch patterns are sub-divided into two types: The simple (or, plain) arch (A) pattern which is composed of ridges that cross the fingertips from one side to the other without recurring and the more intricate type, wherein, the ridges meet at a point, so that, their smooth sweep is interrupted and a tented arch (T) is formed. ${ }^{6,8}$ The most common pattern on the fingertip is the so-recognized loop pattern [Fig 1]b. In this configuration, a series of ridges enter the pattern area on the same side. If the ridges open-up on the ulnar side, the resulting loop is termed as ulnar loop while if they open-up towards the radial margin, it is termed as a radial loop. A loop has a single triradius which is located laterally on the fingertip and always on the side, where the loop is closed. ${ }^{6,8}$ The ridges in a simple whorl are commonly arranged as a succession of concentric rings. Such patterns are described as concentric whorls [Fig 1]c. Also, they might be seen in a different 
configuration with spirals around the core in either a clockwise or, a counter clockwise direction and this type of pattern is called as a spiral whorl. ${ }^{6}$

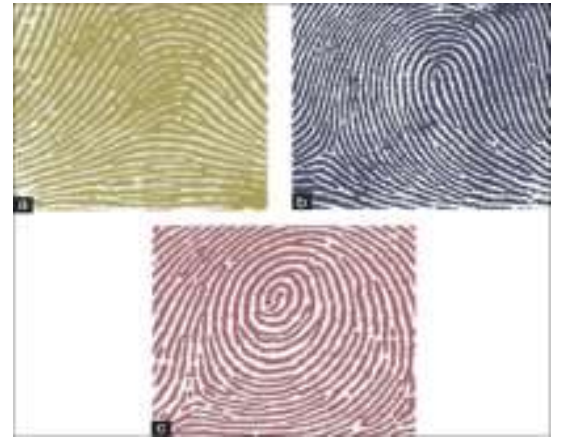

Figure:- 1a,1b,1c

\section{Dermatoglyphic landmarks}

The basic dermatoglyphic landmarks found on the fingertip patterns are the triradii and cores. Triradii are formed by the confluence of three ridge systems [Fig 2]. The geometric center of a triradius is designated as the triradial point. The triradial point forms one terminus of the line along which ridges are counted. These are commonly observed in the HY areas of the palms. ${ }^{6}$ Another important landmark employed in ridge counting is the core which is in the approximate center of the pattern. The cores may be of different shapes. In a loop pattern, the core is usually represented by a straight, rod-like ridge or, a series of two or, more such parallel ridges over which other recurring ridges pass. If a straight ridge is absent in the center of the loop, the innermost recurring ridge is designated as a core. In a whorl, the core can appear as a dot or, a short ridge (either straight or, bent) or, it can be shaped as a circle or, an ellipse in the center of the patterns. In ridge counting, not the whole core, but the point of core only is used. The point of core is at the distal tip of the straight line forming the core. When the innermost recurring ridge contains no ending ridge, the point of core is placed on the shoulder of the loop farther from the triradial point. The shoulders of a loop are the points at which the recurring ridge definitely curves. When an even number of rod-like ridges is present, the point of core is placed on the end of one of the two center ridges farther from the digital triradius. If there are two straight ridges within the innermost recurring ridge, one of which does not rise as high as the shoulder of the loop, the tip of the other ridge is chosen as the point of core. When an uneven number of rods make up the middle of the pattern, the point of core is the tip of the central rod-like ridge. The recurring ridges representing the core must have no appendage connected perpendicularly to their tip on the outside. In presence of such an appendage, the loop is considered spoiled and the next loop outside is considered in locating the point of core. Also, two recurring ridges side by side at the center of the pattern are treated as one loop with two rods within the re-curve. The rod, farther, from the triradius, in such a case, is chosen as carrying the point of core. ${ }^{6}$

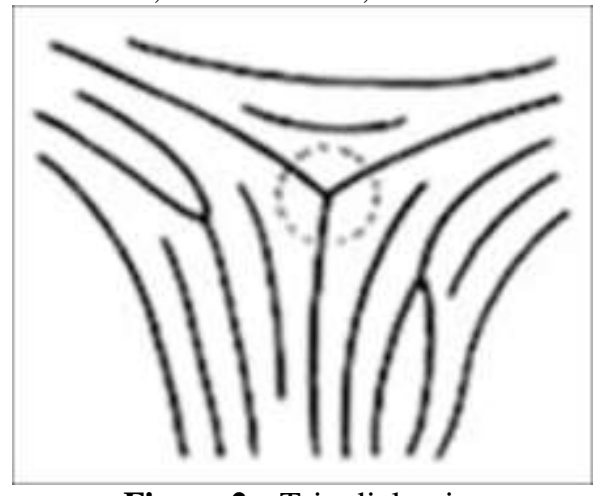

Figure 2:- Triradial point

Methods of recording: Three methods of recording have been used for taking prints: Inkless methods (Walker 1957)

- The Holister system for the young and new born infants

- The Indian ink method (Cumins and Midlow, 1961). 
Inkless methods (Walker 1957)

MacArthur and Ford (1937) described a procedure for making prints in the latent form from face cream which was spread on a kymograph paper. The latter was fixed in shellac after developing an impression with lamp black fine powder. This saved the subject from the inconvenience of the staining or, the discoloration of the hands. ${ }^{10}$ The X-ray (Roentgen's method) has scored its useful value over other unsuccessful techniques for finger prints in the advanced states of decomposed bodies. X-ray records are used for the indirect correlation of the position of the triradii and the hand skeleton by fastening lead pallets with adhesives at the point of the triradii. ${ }^{10}$ Castellanos (1939) mentioned Beclare's procedure which consisted of smearing the skin with lanolin and bismuth carbonate and taking shadow graphs by the usual X-ray method. ${ }^{10}$

\subsection{The Holister system for the young and new born infants}

In infants, prints have been developed on photographic paper from a moistened blotter which is pressed against the fingers and passed through a developing mixture which is prepared from a stock solution which consists of sodium sulphide, NaoH, starch and distilled water. This is made permanent by fixation in hypo solutions. ${ }^{10}$

\section{Inkmethods}

One of the best known and most widely used methods utilizes printer's ink and a good quality paper along with a roller, a glass and/or, metal inking slab and a sponge rubber pad. A small amount of ink is spread over the slab with the roller into a thin, even film. The area to be printed is pressed against the slab and then, pressed against the paper placed over the rubber pad. ${ }^{10,11}$

\subsection{Studies based on Dermatoglyphics to identify various systemic disorders}

Neiswanger et al. conducted a case control study in Chinese individuals with non-syndromic cleft lip with or, without cleft palate (CL/P) and the control groups. Increased radial and ulnar loops were observed in cleft lip and palate patients. ${ }^{12}$ Sugerman et al. observed wider atd angles. ${ }^{13}$ Mathew et al. found an increased frequency of ulnar and radial loops than the arches and whorls in cleft lip with or, without cleft palate patients compared to controls. $^{12}$ ImeneNamouchi conducted a study on Tunisian population to analyze eventual differences between men and women and between individuals according to their geographical distribution.

The Chi-square test revealed highly significant differences between the sexes for the frequencies of arches in case of fifth finger and for the frequencies of loops in case of fourth left finger and the first left finger. The difference of distribution of the whorl pattern between men and women was statistically significant for the fourth left finger while no significant difference was found between sexes in regards of finger ridge counts. ${ }^{14}$ Luna and Pons et al. conducted a study and described an Eastern Andalusia population by more of the whorls and radial loops in males while arches and ulnar loops in females. ${ }^{14}$ Igbigbi and Msamati et al. investigated the South African populations with regards to the digital patterns. In Zimbabwean subjects, ulnar loops were the most predominant pattern type in both sexes followed by whorls in males and arches in females; however the sex differences between the digital pattern types were not found to be statistically significant. ${ }^{14}$ Sontakke et al. found significant reduction of loops in Klinefelter's syndrome patients $(31.7 \%)$ as compared to that of controls. A significant increase of whorls in Klinefelter's syndrome patients $(66.7 \%)$ as compared to that of controls $(35.0 \%)$ was also observed. A similar finding was reported by a study on Japanese patients with Klinefelter's syndrome. ${ }^{15}$

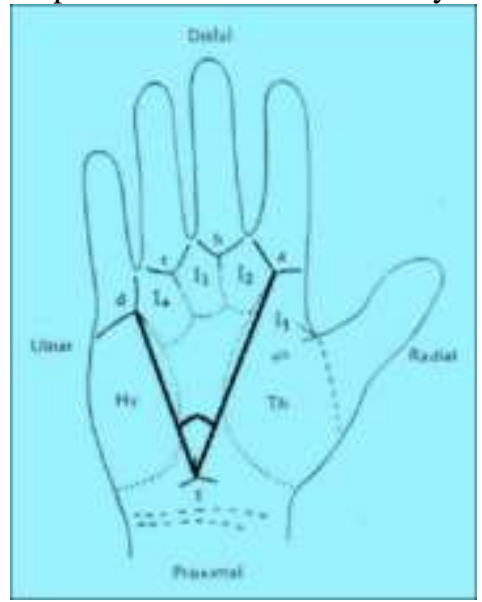

Figure 3:- ATD angle 
Bhargava et al. conducted a study on dental caries group and found highly significant differences in the distribution of loops between the subjects (dental caries group) as against the control group and also observed significant differences between the subjects and control groups for the microbial growth. ${ }^{6,16}$ Ramesh et al. observed TFRC (Total Finger Ridge Count)and ATD angles (ATD angle is formed by lines drawn from the digital triradius (a) to the axial triradius (t) and from this triradius to the digital triradius (d) [Fig 3])with a significant increase in sickle cell anemia patients concluding sickle cell anemia to have dermatoglyphic correlation and that the same could be considered as marker for male as well as female patients as the diagnostic tool in linking sickle cell anemia to dermatoglyphics. ${ }^{17}$ PadminiPramila et al. observed an increased incidence of atd angle in male diabetics than the controls although no significant difference was observed for the same in female patients as against the controls. ${ }^{18}$ On the contrary, Verbov et al. in a study found an increased arch pattern in female diabetic patients only. Sant (1983) reported a significant increase in the frequency of whorls and decrease in ulnar loops in diabetics of both sexes and found a significant increase in arch pattern in female diabetes only. InamdarVaishali et al. (1995), in his study with 158 Insulin Dependent Diabetes Mellitus (IDDM) children with limited joint mobility, found a higher frequency in the number of arches in the patients than in the controls. ${ }^{18}$ Ravidranath et al. (1995) observed, in a study on 150 nonNIDDM patients, an increase in the ulnar and radial loops and a decrease in whorls in diabetics of both the sexes. ${ }^{18}$ PadminiPramila et al. also observed an increased incidence of variations in ulnar loops, simple arches, composite whorls and double pocket whorls in diabetic patients than in the controls. ${ }^{18}$ Igbigbi and Msamati et al., in their study in 2002 on sub-Saharan Africans, also showed the values of TFRC found among the Zimbabweans to be higher in the men than in women. These results were also comparable to those obtained in the Zulus of South Africa. ${ }^{14}$ Igbigbi and Msamati et al., in their study in 1999 on Southern Nigerians, stated the Southern Nigerians to have a significantly higher TFRC than those previously reported for the Zulu. In Malawian subjects, women had significantly higher TFRC than men. ${ }^{14}$ Arunpongpaisal and Nanakorn, in their study, showed that only male schizophrenics had a significantly less proportion of whorl pattern than the controls, the findings which were consistent with the Paez's study. ${ }^{19}$ Schauman and Mayersdorf et al. found an increase in radial loops in white adults with idiopathic epilepsy. ${ }^{20}$ AndaniRashida and et al., in their study, showed 'atd' angle to be wide in Thalassemia patients in comparison to the controls. ${ }^{21}$ SinghalManju D and Gandotra A showed a significant difference of atd angle in the right hand in leprosy patients as compared to the control group. The findings of the study, however, revealed significant differences of the atd angle in the left hand in leprosy patients as against the control group. $^{22}$ Bukelo et al. reported an increase of arches and a decrease of ulnar loops in the fingertips of a group of patients with an acute blast cell leukemia. ${ }^{23}$ Ramesh et al. observed a significant increase in TFRC and ATD angle sickle cell anemia patients as against the controls. ${ }^{19}$ Reddy et al. also reported an increase in TFRC $(P<0.001)$ in carcinoma cervix patients as compared to controls. ${ }^{19}$ InamdarVaishali et al. conducted a study on ninety histopathologically established females of cancer cervix and ninety normal healthy females (control group). In both patients and controls, the age-range was between 25 and 65 years. The results of the study showed a significant increase in the frequency of whorls and TFRC in both hands and an increase in the frequency of arches in left hand with a significant decrease in atd angle and ridge count and frequency of ulnar loops in both hands of females having carcinoma of cervix as compared to the controls. There was no significant difference although that could be observed in relation to other parameters like $a-b, b-c, c-d$ ridge counts and radial loop frequency between the patients and controls. ${ }^{19}$ AndaniRashida and et al., in their study, showed 'atd' angle to be wide in Thalassemia patients in comparison to the controls. ${ }^{21}$ Bukelo Mario Joseph et al. conducted a study on patients with acute lymphoblastic leukemia and controls. The results of the study showed the mean ab ridge count and the mean ATD angle to be higher in cases than the controls. ${ }^{23}$

Since the disease identification or detection and diagnosis is carried out in the past and at present depending upon the dermatoglyphics in medical and scientific researches, there have been few efforts made to correlate the occurrence of different forms of periodontitis and their correlation with the dermatoglyphics, the studies of Yilmaz $\mathrm{S}$, Atasu $\mathrm{M}$ et al ${ }^{24,25}$ studies have indicated a possible relation with the pattern of finger print and type of periodontitis, we have conducted this study to investigate the relevance of the previous studies in interlinking the dermatoglypic findings with the type of periodontitis to test the application of this principle in the patients visiting the postgraduate department of periodontics in Meghana institute of dental sciences, Nizamabad.India. 


\section{Methodology:-}

A total of 25 patients with chronic generalized periodontitis and 25 patients with generalized aggressive periodontitis were included in the study.Fingerprint patterns of the study subjects were obtained by ink - stamp method given by Cummins and Midlo.The 3 basic types of ridge patterns found in the distal phalanges of the digits whorls, loops and arches were calculated.

\section{Results:-}

The data obtained were stastistically analysed using Chi square test. (Table 1).

Within the limitations of the present study, an increased frequency of ulnar loops were found on all fingers of patients with aggressive periodontitis and an increased frequency of whorls and ulnar loops were found on all fingers of patients with chronic periodontitis.

\begin{tabular}{|l|l|l|l|l|}
\hline & \multicolumn{2}{|l|}{ Chronic Periodontitis } & \multicolumn{2}{l|}{ Aggressive Periodontitis } \\
\hline & No. & $\%$ & No. & $\%$ \\
\hline ARCHES & 22 & $8.80 \%$ & 34 & $13.60 \%$ \\
\hline ULNAR LOOPS & 89 & $35.60 \%$ & 109 & $43.60 \%$ \\
\hline RADIAL LOOPS & 22 & $8.80 \%$ & 15 & $6.0 \%$ \\
\hline WHORLS & 117 & $46.80 \%$ & 92 & $36.80 \%$ \\
\hline
\end{tabular}

Table 1:-

\section{Discussion:-}

Studies on inheritance of dermatoglyphics by qualitative and quantitative methods have shown great resemblance among monozygotic twins and reasonably strong inheritance among siblings and parents. Because of the great diversity in the types and combinations of patterns found on the fingers, palms and soles, it is evident that the formation of the dermal ridges would be determined by many genes spread over many chromosomes ${ }^{26}$. Yilmas $\mathrm{S}$ et al ${ }^{24}$ performed a study on 36 Early onset periodontitis and 20 adult periodontitis patients and 20 periodontally healthy individuals. The study elaborated dermatoglyphics, which is a genetic test method, suggesting the modes of inheritances of hereditary diseases. The diagnostic value of this genetic test method, which is the study of the quantitative and qualitative characteristics of patterns of ridged skin, and the role of heredity on periodontal diseases were discussed. Atasu $\mathrm{M}$ et al ${ }^{25}$ in 2005 compared the finger-tip patterns of the juvenile Periodontitis (JP) patients with those of periodontally healthy individuals. They reported decreased frequencies of twinned and transversal ulnarloops on all fingers of the patients with juvenile Periodontitis, a decreased frequency of double loops on all fingers and an increased frequency of radial loops on the right second digits of the patients with Rapidly progressing Periodontitis (RPP), and the increased frequencies of concentric whorls and transversal ulnar loops on all fingers of the patients with Adult periodontitis, an increased frequency of $\mathrm{t}^{\prime \prime}$ triradii on the palms of the patients with JP, the increased frequencies of IV and $\mathrm{H}$ loops and tbtriradii on the palms of the patients with RPP and an increased frequency of e triradii on the soles of the patients with JP. ${ }^{25}$

\section{Conclusion:-}

Within the limitations of the study, it was found that certain finger tip patterns were in greater frequency in aggressive periodontitis patients. However, further studies with larger sample size are required to arrive at a conclusive report linking dermatoglyphic patterns in aggressive periodontitis.

\section{References:-}

1. Prabhu N, Issrani R, Mathur S, Mishra G, Sinha S. Dermatoglyphics in health and oral diseases - A review. JSM Dent 2014;2(4):1-5.

2. Galton F. Finger prints. London: McMillan; 1982

3. Osunwoke EA, Ordu KS, Hart J, Esomonu C, Tamunokuro FB. A study on the dermatoglyphic patterns of Okrika and Ikwerre ethnic groups of Nigeria. SciAfr 2008;7:143-7

4. Birnholz JC. Dermatoglyphics in congenital heart disease. Am J Roentgenol Radium TherNucl Med 1972;116:539-47.

5. Kumbnani HK. Dermatoglyphics. In: Bhasin V, Bhasin MK, editors. Delhi: Kamla-Raj Enterprises; 2007

6. Soni A, Singh SK, Gupta A. Implications of dermatoglyphics in dentistry. J DentofacialSci 2013;2:27-30 
7. Osunwoke EA, Ordu KS, Hart J, Esomonu C, Tamunokuro FB. A study on the dermatoglyphic patterns of Okrika and Ikwerre ethnic groups of Nigeria. SciAfr 2008;7:143-7

8. Ramani P, Abhilash PR, Sherlin HJ, Anuja N, Premkumar P, Chandrasekar T, et al. Conventional dermatoglyphics- Revived concept: A review. Int J Pharma Bio Sci 2011;2:446-58.

9. Babler WJ. Embryologic development of epidermal ridges and their configurations. Birth Defects Orig Artic Ser 1991;27:95-112.

10. Sharma MK, Hemlata D. Dermatoglyphics: Diagnostic tool to predict diabetes. J ClinDiagn Res 2012;6:327-32

11. Venkatesh E, Anjana B. Palmar dermatoglyphics in oral leukoplakia and oral squamous cell carcinoma patients. J Indian Acad Oral Med Radiol 2008;20:94-9

12 Neiswanger K, Cooper ME, Weinberg SM, Flodman P, Keglovits AB, Liu Y, et al. Cleft lip with or without cleft palate and dermatoglyphic asymmetry: Evaluation of a Chinese population. OrthodCraniofac Res 2002;5:140-6

13 Sugerman PB, Savage NW, Walsh LJ, Zhao ZZ, Zhou XJ, Khan A, et al. Oral lichen planus: Causes, diagnosis and management. Aust Dent J 2002;47:290-7

14 Namouchi I. Anthropological significance of dermatoglyphic trait variation: An intra-Tunisian population analysis. Int J Mod Anthropol 2011;4:12-27.

15 Sontakke BR, Ghosh SK, Pal AK. Dermatoglyphics of fingers and palm in Klinefelter's syndrome. Nepal Med Coll J 2010;12:142-4.

16 Bhargava SS, Sathawane RS. Dermatoglyphics: Exploring newer dimensions in diagnosis. Cent India J Dent Sci2012;3:126-32.

17 Ramesh M, Kumari KG, Kalpana VL, Sudhakar G. Palmar and digital dermatoglyphic patterns in sickle cell anemia patients of North Coastal Andhra Pradesh, South India. J Anthropol 2012;8:23-32.

18 InamdarVaishali V, Vaidya SA, Pratima K, Devarshi DB, Shailesh K, TungikarSudhir L. Dermatoglyphics in carcinoma cervix. J AnatSoc India 2006;55:57-9.

19 Arunpongpaisal S, Nanakorn S. Dermatoglyphic traits in Thai schizophrenia patients: A matching case-control study. J Thai Med Assoc 2011;94:386-94.

20 Mattos-Fiore MA, Saldanha PH. Dermatoglyphics in juvenile epilepsy. Braz J Genet 1996;19:151-63.

21 AndaniRashida H, Dharati K, Ojaswini M, Nagar SK, Kanan U, Bhaskar P. Palmar dermatoglyphics in patients of thalassemia major. Natl J Med Res 2012;2:287-90.

22 SinghalManju D, Gandotra A. An early predictor in leprosy: The ATD angle. J AnatSoc India 2010;59:201-4.

23 Bukelo MJ, Kanchan T, Rau AT, Unnikrishnan B, Bukelo MF, Krishna VN. Palmar dermatoglyphics in children with acute lymphoblastic leukemia - A preliminary investigation. J Forensic Leg Med 2011;18:115-8.

24 Yilmaz S, Atasu M, Kuru B. A genetic and dermatoglyphics study on periodontitis. J Marmara Univ Dent Fac. 1993 Sep;1(4):297-306

25 Atasu M. Kuru B. E. FiratliH. Meriç.Dermatoglyphic findings in periodontal diseases. Int. J. Anthropol.(2005) 20: 63.

26 Uchida IA, Soltan HC. Evaluation of dermatoglyphics in medical genetics. Pediatric Clinics of North America 1963; 10: 409-21. 